\title{
Potential climate change mitigation of Indian Construction Industry through a shift in energy efficient technology by 2050
}

\author{
Priyanka Jajal $^{1}$ and Trupti Mishra ${ }^{1,2}$ \\ ${ }^{1}$ Interdisciplinary Programme in Climate Studies, Indian Institute of Technology Bombay, Mumbai-400076, India \\ ${ }^{2}$ Shailesh J. Mehta School of Management, Indian Institute of Technology Bombay, Mumbai-400076, India \\ Correspondence: Priyanka Jajal (jajal.priyanka@gmail.com)
}

Received: 30 May 2018 - Revised: 25 July 2018 - Accepted: 30 July 2018 - Published: 21 August 2018

\begin{abstract}
Climate change is a growing concern that is attracting international efforts. India, as a developing country, has committed to reducing its emission intensity of GDP up to $30 \%-35 \%$ by 2030 . The emission intense sectors would be targeted to achieve climate commitment. One of the emission intense sector is construction raw material manufacturing that contributes $10 \%$ share in the total emissions making it one of the potential mitigation sector. The study examines emissions from the construction raw materials namely, cement, steel, and brick manufacturing and presents two emission scenarios up to 2050. Energy efficient scenario (S2) is compared with a reference scenario (S1) developed based on a bottom-up approach. The results indicate that a moderate energy efficiency improvements and technological shifts lead to a decrease in emissions of $72 \mathrm{MTCO}_{2}$ by 2030 and $137 \mathrm{MTCO}_{2}$ by 2050 . Further, the steel industry has the highest reduction potential, as the current technologies are energy inefficient. Similarly, the current dependency on fired bricks may be shifted to cement setting blocks leading to emission reductions. Cement manufacturing, on the other hand, shows limited scope for emission reduction that may be achieved through energy efficiency improvements. Efforts towards energy efficiency improvements in construction raw material manufacturing would result in reductions beyond the existing commitment of the Paris Agreement for India by 2030 .
\end{abstract}

\section{Introduction}

Climate change and global warming are one of the pressing issues in today's world. The Paris Agreement has been negotiated amongst countries to determine individual com- mitment towards the climate change mitigation. India, which is one of the developing countries, has played an important role in negotiations. The country has committed to reducing the emission intensity of GDP by $30 \%-35 \%$ in 2030 compared to 2005 levels (Government of India, 2015). Intended Nationally determined Contributions (INDC) and other national policies towards climate change mitigation commitment would drive the efforts towards achieving the goals.

The construction industry is a major contributor to the economy (8\% of total GDP, 2014) as well as GHG emissions (10\% of total emissions, 2010) (Asian Development Bank, 2015; Ministry of Environment, Forest and Climate Change, 2015) in India. Raw materials required for construction include cement, steel and brick, which involve energy intensive production processes (Dutta and Mukherjee, 2010; Rajarathnam et al., 2014). Even though the estimates of emissions from these processes are not consistent with the literature, understanding future mitigation opportunities requires attention (INCCA, 2010; Ministry of Environment, Forest and Climate Change, 2015).

Emissions from cement manufacturing in India have been studied using bottom-up approach (Bhushan, 2009a; Dutta and Mukherjee, 2010; Hasanbeigi et al., 2013; Sathaye et al., 2005) and system dynamics approach (Anand et al., 2006). Majority of the studies have looked at the energy requirements for cement production at present and future, to determine energy and emission reduction potentials (Bhushan, 2009a; Dutta and Mukherjee, 2010; Sathaye et al., 2005). On the other hand, various emerging technologies and improvements along with their associated costs have been assessed by Hasanbeigi et al. (2012) to understand their role in the future industrial development. Cement and Steel manufacturing have been addressed together using a bottom-up ap- 
proach, where energy efficiency improvements, $\mathrm{CO}_{2}$ emissions reductions and related costs are considered (Morrow et al., 2014).

Similarly, steel industrial energy consumption has been addressed by Hidalgo et al. (2006) and Bhushan (2009b) using a bottom-up approach. Contrary to cement and steel studies, emission factor determination (Rajarathnam et al., 2014) as well as process reporting (Maithel, 2013) has been studied for brick manufacturing. Emissions from the brick industry have not been addressed in the literature so far. Hence, this study estimates emissions from the manufacturing of cement, steel, and brick for the purpose of construction, in present (2015) and for the future (2050) in two scenarios, one reference scenario and second moderate energy efficient scenario.

The first section has introduced importance of the construction sector for the study along with an overview of the latest literature on cement and steel emissions from the country. Next section delves into the existing framework used for sectoral emission analysis and introduces the conceptual framework used for this study. Further, the third section details out the methodology of energy requirement and emission generation. For the purpose, relevant assumptions are tabulated along with the logic behind scenario development. Results and discussion section presents the energy use and emissions derived using the methodology for both the scenarios. An elaborate discussion is undertaken by comparing the results of the present study with the literature to derive the conclusion. A brief policy suggestion is given in the conclusion section.

\section{Conceptual Framework}

Emissions from construction industry have been addressed at two scales, one at a single building or a complex level and second at the country level. The literature identifies two approaches to estimate sectoral emission at a country scale: top-down and bottom-up. The top-down approach considers a country as an economy and divides its functions for a sector to estimate the emissions from a demand and supply equilibrium (Antimiani et al., 2015; Chen et al., 2016; Li and Jia, 2016; Montaud et al., 2017). Compound General Equilibrium (CGE) is one of the models developed based on a top-down approach where various components of the economy such as labour, market, and consumer interact (Antimiani et al., 2015). Such models help assess shifts in emissions as a result of a policy implementation (Antimiani et al., 2015; Chen et al., 2016; Li and Jia, 2016; Montaud et al., 2017). The top-down approach does not incorporate details related to technologies and their specific emissions making it unsuitable for the purpose of this study.

The other approach is bottom-up which requires technological details of a single sector to be aggregated at the country level to estimate sectoral emissions (Kumar and Madlener, 2016; Tapia-Ahumada et al., 2015; Wang et al.,
2014). LEAP, AIM, and MARKAL are some of the models that are based on the principles of bottom-up approach. These models have structured data requirement along with a specific set of assumptions to the given sector. Hence, to overcome limitations of the available models under bottomup approach, case and objective specific models have been developed by various authors in previous literature (He and Wang, 2017; Hidalgo et al., 2005; Ozawa et al., 2002; Pardo et al., 2011; Rojas-Cardenas et al., 2017; Wang et al., 2007; Worrell et al., 2001). The present study develops a specific model based on a bottom-up approach specific for construction raw materials.

\section{Methodology}

The study develops a bottom-up model using technological bifurcation, energy factors and emission factors for each of the raw materials (cement, steel, and bricks) of the construction industry. A separate set of equations and assumptions are applied to each raw material with the same framework which is explained here along with the equations. Production of each material is divided into a share of each technological production using their overall share in the industry (Eq. 1). Once the individual production is available, energy requirement (Eq. 2) and emission factors (Eq. 3) for each technology are used to calculate total emissions. However, a different approach needs to be applied for cement industry as emissions are caused by two sources of the production: (i) calcinations process to produce clinker and (ii) energy use throughout the production process. Hence, clinker production is derived from the clinker share of each technology (Eq. 4) and emissions generated during clinker production (Eq. 5). The energy use in terms of thermal or electric is calculated from the total production (Eq. 2).

$$
\begin{aligned}
& P_{i, t}=P_{\text {total }, t} \times S_{i, t}, \\
& E_{i, t}=P_{i, t} \times \mathrm{EnF}_{i}, \\
& \mathrm{Em}_{i, t}=P_{i, t} \times \mathrm{EF}_{i} \\
& C_{i, t}=P_{i, t} \times C_{\mathrm{S}} \\
& \mathrm{Em}_{\mathrm{c}, \text { total }, t}=\sum_{i}\left(C_{i, t} \times \mathrm{EF}_{C}\right)+\left(E_{i, t} \times \mathrm{EF}_{i}\right) \\
& \mathrm{Em}_{\text {total }, t}=\sum_{i}\left(\mathrm{Em}_{i, t}\right) \\
& E_{\text {total }, t}=\sum_{i}\left(E_{i, t}\right)
\end{aligned}
$$

Where, $P_{i, t}$ is the production coming from technology $i$ at time $t ; P_{\mathrm{total}, t}$ is the total production at time $t$ for cement, steel and brick industry; $S_{i, t}$ is the share of technology $i$ at time $t$ for cement, steel and brick manufacturing technologies; $\mathrm{EnF}_{i}$ is energy factor for technology $i$ constant over time; $E_{i, t}$ is energy required for production coming from technology $i$ at time $t ; \mathrm{EF}_{i}$ is emission factor for technology $i$ constant over the time period for all the raw materials; $\mathrm{Em}_{i, t}$ 
Table 1. Production technologies for cement, steel and brick manufacturing with their share (percentage) in India in 2015, energy factors $\left(\mathrm{GJ} \mathrm{MT}^{-1}\right)$ and emission factors $\left(\mathrm{tCO}_{2} \mathrm{t}^{-1}\right)$.

\begin{tabular}{|c|c|c|c|c|}
\hline Sr. no & Technology & Energy factor & Emission factor & Share (2015) \\
\hline \multicolumn{5}{|c|}{ Cement (Source: Bhushan, 2009a) } \\
\hline 1 & Ordinary Portland Cement (OPC) $(95 \%)$ & \multirow[b]{2}{*}{$3.1 \mathrm{GJ} \mathrm{MT}^{-1} \&$} & \multirow{2}{*}{$86.5 \mathrm{t} \mathrm{GJ}^{-1}$} & $56 \%$ \\
\hline 2 & Pozzolanic Portland Cemnet (PPC) $(80 \%)$ & & & $31 \%$ \\
\hline 3 & Portland Slag Cement (PSC) (45\%) & \multirow[t]{2}{*}{$82 \mathrm{kWh} \mathrm{MT}^{-1}$} & \multirow{2}{*}{$0.99 \mathrm{~kg} \mathrm{kWh}^{-1}$} & $12 \%$ \\
\hline 4 & Others $(90 \%)$ & & & $1 \%$ \\
\hline \multicolumn{2}{|c|}{ Steel (Source: Morrow et al., 2014) } & Energy $\left(\mathrm{GJ} \mathrm{MT}^{-1}\right)$ & $\mathrm{EF}\left(\mathrm{tCO}_{2} \mathrm{t}^{-1}\right.$ steel $)$ & \\
\hline 1 & Electric Arc Furnace (EAF) - scrap based & 6 & 0.5 & $14 \%$ \\
\hline 2 & EAF - gas based & 15.9 & 1.55 & $11 \%$ \\
\hline 3 & EAF - Coal based & 17 & 3.1 & $26 \%$ \\
\hline 4 & Blast Furnace - Basic Oxygen Furnace (BF-BOF) & 16.4 & 2.8 & $49 \%$ \\
\hline \multicolumn{2}{|c|}{ Brick (Source: Venkataraman et al., 2018) } & Energy ( $\mathrm{MJ} \mathrm{kg}^{-1}$ brick) & $\mathrm{EF}\left(\mathrm{tCO}_{2} \mathrm{t}^{-1}\right.$ brick $)$ & \\
\hline 1 & Clamps & 1.22 & 0.23 & $25 \%$ \\
\hline 2 & Bull's Trench Kiln (BTK) & 2.91 & 0.1 & $66 \%$ \\
\hline 3 & zig-zag firing & 1.05 & 0.1 & $8 \%$ \\
\hline 4 & Vertical Shaft Brick Kiln (VSBK) & 0.74 & 0.1 & $1 \%$ \\
\hline 5 & Cement blocks & 142.4 & 0 & $0 \%$ \\
\hline
\end{tabular}

is emissions from the production of $P_{i}$ at time $t ; C_{\mathrm{S}}$ share of clinker required for the type of cement $i ; C_{i, t}$ Clinker production required for cement type $i$ at time $t ; \mathrm{Em}_{C}$ is emission factor of clinker production; $\mathrm{Em}_{\mathrm{c}, \text { total }, t}$ is the total emissions from total cement production at time $t ; \mathrm{Em}_{\mathrm{total}, t}$ represents the total emissions from the total production of $P_{\text {total }}$ at time $t$ for steel and brick; $E_{\text {total }, t}$ is the total energy required for the production of $P_{\text {total }}$ at time $t$ for cement, steel, and brick.

The technologies of production for cement, steel, and brick along with the energy and emission factors are listed under Table 1 . The share of clinker required from each cement technology is indicated in the brackets. The energy and emissions have been estimated for 2015 (present) using the present share of technologies (given in Fig. 1b) where the current cement, steel and brick productions are 238 MT, $99 \mathrm{MT}$ and 250 billion respectively (CMIE, 2017).

Two scenarios are developed with the modified share of technology for each raw material. The scenarios are called: reference scenario (S1) and moderate energy efficient scenario (S2). Future productions of cement, steel, and bricks are assumed to be constant for both the scenarios, where the production growth rates are derived from the literature. During 2015 to 2030 the production grows at $7.7 \%, 6 \%$ and $6 \%$ for cement, steel, and bricks respectively (CMIE, 2017). In the long run, the demand of materials is expected to decrease with stabilization in the population and GDP growth. Hence, the growth of production is reduced to $5 \%, 3 \%$ and $3 \%$ for cement, steel, and bricks respectively from 2030 to 2050 .

Reference scenario is developed based on the existing trends of technology shifts and energy efficiency improve- ments. Cement production in the country has been one of the cleanest industries as the energy requirements matches the global standard (Worrell et al., 2007). Thus, a small improvement in the efficiency is expected in the future compared to reference scenario (Fig. 1a). Thermal and electric energy efficiency changes assumed under this study are lower than that assumed under Bhushan (2009a); whereas the energy efficiency is in line with that assumed by Dutta and Mukherjee (2010). Overall, changes in the technological distribution are minor as indicated in Fig. 1b.

On the other hand, steel and brick production in India has been energy inefficient, leading to higher emissions. Steel production technologies vary considerably in terms of the energy requirement, where Electric Arc Furnace (EAF) scrap based production is the most efficient. Scrap-based steel production is challenged by limitation of the scrap supply, especially in India. The long-term supply of recycled scrap is expected to increase with increased recycling of steel scraps leading to the total share of $20 \%$ scrap-based steel production (Oda et al., 2012; Shirodkar and Terkar, 2017). Dependency on coal-based EAF plants is also expected to decrease with a slight increase in gas-based plants, which are shown in Fig. 1c.

Brick manufacturing includes burning green bricks directly using coal or other biofuels. Two types of burning take place one where separate batches of bricks are burnt, and second continuous burning. Both the processes require fuel for burning; however, the most efficient bricks are the ones, which are made from setting of cement. As an effort to reduce emissions, the existing inefficient brick kilns are con- 


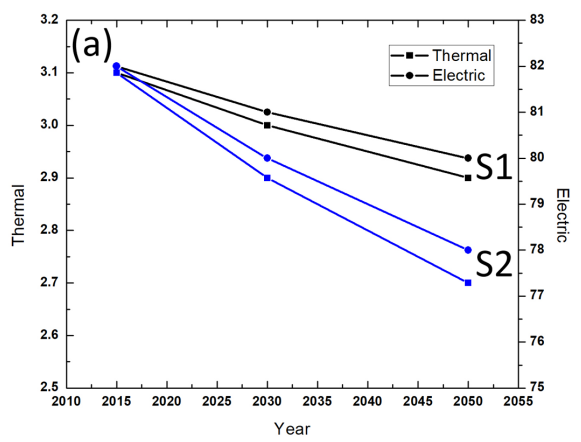

(b)

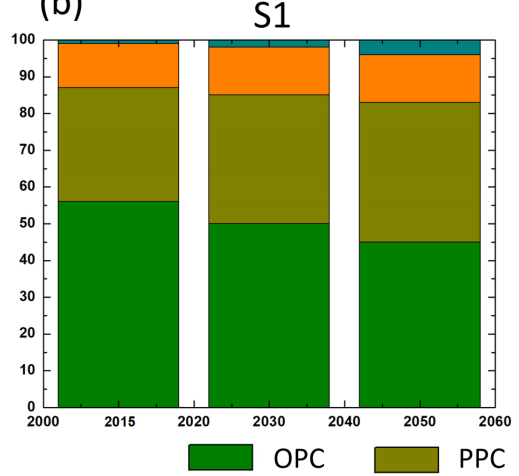

(c)

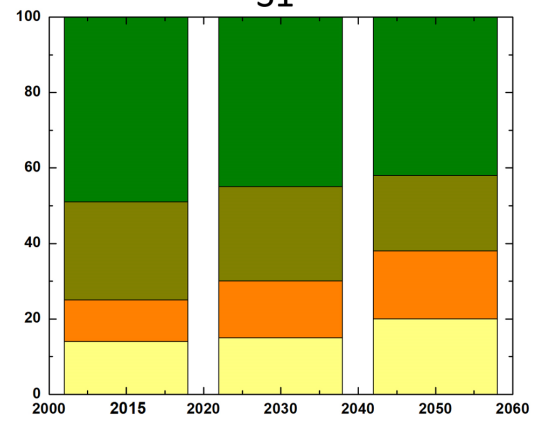

BF-BOF

S1

(d)

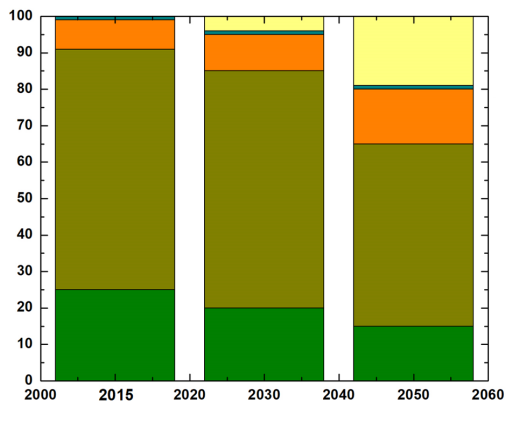

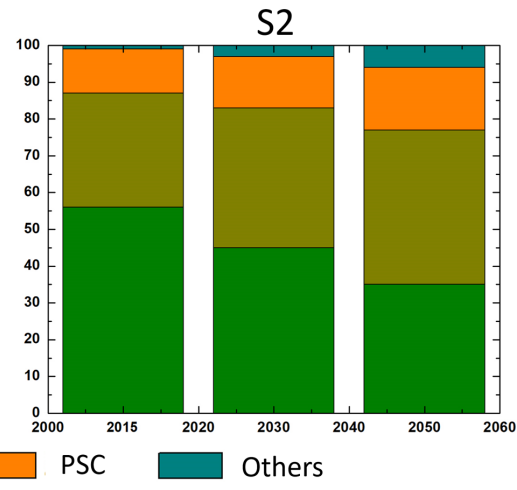

S2

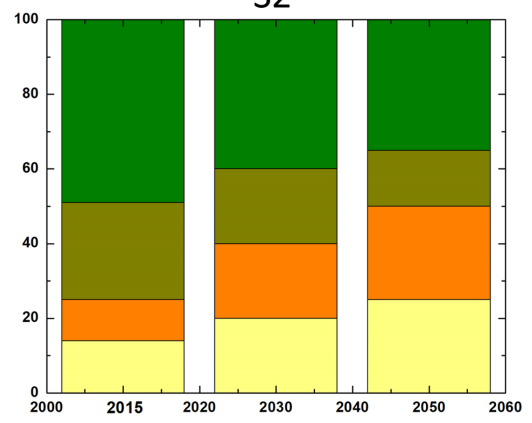

EAF scrap

EAF gas

S2

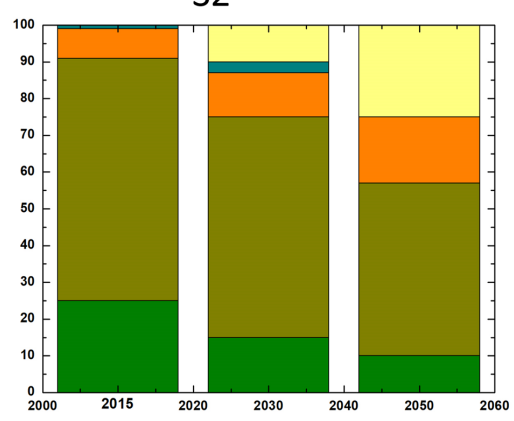

VSBK

Non-fired

Figure 1. Energy efficiency and technological change assumptions for reference scenario (S1) and moderate energy efficient scenario (S2). (a) Thermal and electric energy efficiency changes from 2015 to 2050 for cement manufacturing. Technological changes from 2015 to 2050 under (b) cement industry, (c) steel industry and (d) brick industry. 
verted to energy efficient kilns as a compliance with the government order (Central Pollution Control Board, 2013). The trend is, expected to continue in the reference scenario where distribution of zig-zag and vertical shaft brick kiln (VSBK) is expected to take over the share of clamps and Bull's Trench Kiln (BTK). Non-fired bricks have not appeared in the Indian market until now yet the reference scenario assumes to grow the share up to $20 \%$ by 2050 as non-fired bricks show low material requirements (shown in Fig. 1d).

The second scenario is called a moderate energy efficient scenario (S2). As the name suggests, the scenario has been built to assess the effects of moderate changes in energy efficiency on the energy demand and GHG emissions. As shown in Fig. 1b, energy efficiency improves for cement production along with electric energy efficiency. The technologies can be seen from Ordinary Portland Cement (OPC) towards Portland Slag Cement (PSC) which requires only $45 \%$ of clinker mix (Bhushan, 2009a). Scrap based manufacturing is encouraged in the steel production under $\mathrm{S} 2$, as the scrap availability is expected to increase up to $25 \%$. Similarly, brick production from non-fired manufacturing is also expected to increase up to $25 \%$. The assumptions are based on the reference and other scenarios developed by Venkataraman et al. (2018). The modified scenario assumes a moderate change between their aspirational and ambitious scenarios for cement, steel and brick industry.

\section{Results and discussion}

The emissions from cement manufacturing at present (2015) are estimated to be $203 \mathrm{MTCO}_{2}$ (Fig. 2); which is higher than the estimates given by the government of $124 \mathrm{MTCO}_{2}$ eq. in 2010 (Ministry of Environment, Forest and Climate Change, 2015). However, estimates by Bhushan (2009a) are comparable to the present study emissions. Steel production is high on energy demand, leading to emissions of $239 \mathrm{MTCO}_{2}$. Again, the emissions are quite larger than the estimated emissions of $96 \mathrm{MT} \mathrm{CO}_{2}$ eq. in 2010 by the government (Ministry of Environment, Forest and Climate Change, 2015) and in line with the estimates of Bhushan (2009b). Lastly, brick emissions are estimated at $1.1 \mathrm{MTCO}_{2}$ eq. in the literature, while the present study estimates are $106.8 \mathrm{MTCO}_{2}$ eq. Due to lack of estimates, brick emissions cannot be compared with the literature.

Reference scenario estimates for cement production suggests that the emissions would increase up to 504 and $1315 \mathrm{MTCO}_{2}$ in 2030 and 2050 respectively (Fig. 2). The estimates are comparable to that of business as usual (BAU) scenario by Bhushan (2009a). However, Dutta and Mukherjee (2010) BAU estimates are higher than the present study $\mathrm{S} 1$ for 2030. Moderate changes in the energy efficiency lead to reductions of 7 and $52 \mathrm{MTCO}_{2}$ in 2030 and 2050 respectively under S2. These reductions are $3.9 \%$; however, they are modest compared to the ones estimated by
Table 2. Comparison of emission estimates from present study for cement and steel manufacturing in 2015 and 2030 with the literature.

\begin{tabular}{|c|c|c|c|c|}
\hline \multirow{2}{*}{$\begin{array}{l}\text { Sector } \\
\text { Year }\end{array}$} & \multicolumn{2}{|c|}{ Cement } & \multicolumn{2}{|c|}{ Steel } \\
\hline & 2015 & 2030 & 2015 & 2030 \\
\hline \multicolumn{5}{|c|}{$\begin{array}{l}\text { Ministry of Environment Forest and } \\
\text { Climate Change (2015) }\end{array}$} \\
\hline \multicolumn{3}{|c|}{124.585} & \multicolumn{2}{|l|}{96} \\
\hline \multicolumn{5}{|c|}{ Dutta and Mukherjee (2010) } \\
\hline BAU & & 939 & & 1071 \\
\hline $\mathrm{S} 2$ & & 732 & & 803 \\
\hline \multicolumn{5}{|c|}{ Bhushan $(2009 a, b)$} \\
\hline BAU & 182 & 470 & 208 & 668 \\
\hline $\mathrm{S} 2$ & 142 & 394 & 209 & 608 \\
\hline \multicolumn{5}{|c|}{ Present Study } \\
\hline Ref & 202.5 & 507 & 239 & 554 \\
\hline S2 & 202.5 & 497 & 239 & 509 \\
\hline
\end{tabular}

Bhushan (2009a) and Dutta and Mukherjee (2010) (Table 2). Additionally, the effort towards energy efficiency improvements lead to a reduction of 3 and $5 \mathrm{GJ}$ of thermal energy along with 1.2 and $2.5 \mathrm{kWh}$ electric energy in 2030 and 2050 respectively. The amount of coal saved per year in 2030 and 2050 is calculated to be 167 and $393 \mathrm{~kg}$ respectively, assuming the calorific value to be $18.353 \mathrm{MJ} \mathrm{kg}^{-1}$ of coal and heat rate to be $83.68 \mathrm{MJ} \mathrm{kWh}^{-1}$ (Venkataraman et al., 2018).

The steel industry is estimated to emit $554 \mathrm{MTCO}_{2}$ in 2030 and $930 \mathrm{MTCO}_{2}$ in 2050 under reference scenario (Fig. 2). Estimates of 2030 for Indian steel industry by Dutta and Mukherjee (2010) are much higher at $1071 \mathrm{MT} \mathrm{CO}_{2}$ under BAU and $803 \mathrm{MTCO}_{2}$ under energy efficient scenario. On the other hand, Bhushan (2009a) has estimates comparable to the present study. The differences in results can be attributed to the energy efficiency assumptions. The energy requirements under the present study are expected to increase from 35 MTOE in 2015 to 84 MTOE in 2030 and 146 MTOE in 2050; whereas, $\mathrm{S} 2$ leads to a reduction of $\mathrm{CO}_{2}$ up to 46 and $93 \mathrm{MTCO}_{2}$ in 2030 and 2050 respectively. The energy saved under the S2 equates to coal saving of $7 \mathrm{MT}$ in 2030 and $13.5 \mathrm{MT}$ in 2050 . The energy savings are low at $9 \%$, which result in emission reductions of $18 \%$ to $22 \%$. The estimates for steel industry are comparable to that under Bhushan (2009b) as 2030 estimates for the BAU scenario is $668 \mathrm{MT} \mathrm{CO}_{2}$ along with $9 \%$ reduction potential for low carbon (LC) scenario.

Lastly, under the reference scenario emissions from brick industry is expected to double by 2030 at $208 \mathrm{MTCO}_{2}$ and increase to $302 \mathrm{MTCO}_{2}$ by 2050 (Fig. 2). The changes in technologies of production under $\mathrm{S} 2$ results in a reduction of 

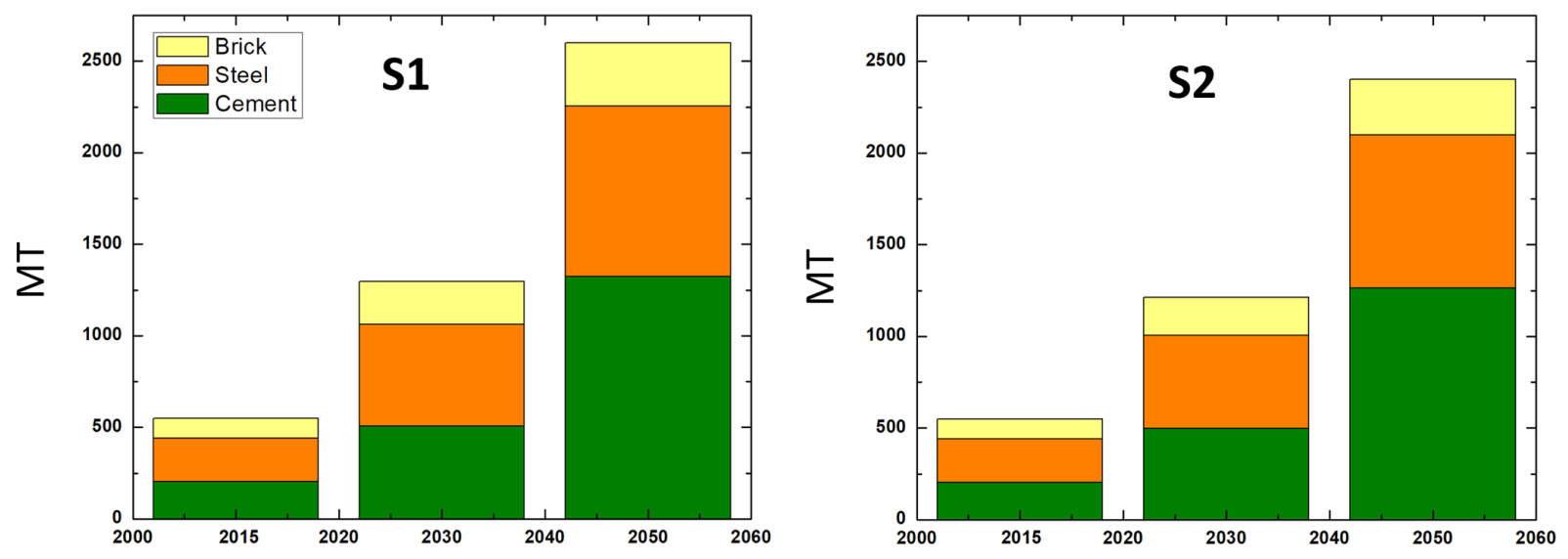

Figure 2. Total emission estimation under Reference scenario (S1) and moderate energy efficient scenario (S2) over study period of 2015 to 2050 in $\mathrm{MT} \mathrm{CO}_{2}$ with sectoral distribution.

27 and $44 \mathrm{MT} \mathrm{CO}_{2}$ by 2030 and 2050 respectively. However, the energy requirement increases from the reference scenario to $\mathrm{S} 2$ as the non-fired bricks would also require energy to produce cement. It is clear that brick manufacturing may lead to increased use of coal with a reduction in emissions.

\section{Conclusion}

India is committed towards the climate change mitigation under the Paris Agreement, under which various initiatives are undertaken. The present study is an effort to quantify emissions and emission reduction strategy of the raw materials used for construction industry. For this, $\mathrm{CO}_{2}$ emissions from cement, steel, and brick manufacturing are estimated. Further, emission estimates are used to develop two scenarios: (i) a reference scenario (S1) with an extension of the present policies and (ii) a moderate energy efficient scenario (S2) where moderate changes in efficiencies and technologies are assumed. The focus of the scenarios is to underline emission reduction strategies and policy guidelines rather than estimating the exact emissions in future.

The study adopts, a bottom-up approach using annual production information, growth rates of production increase, technology distribution in present and future, and energy factors along with emission factors for each technology. The reductions under S2 are low for all the three manufacturing products. However, the study helps identify future guidelines for policy formulations. The cement industry is already at par with the world standards of efficiency and hence the emissions. The scope for improvement is less; although, the natural shifts in energy efficiency should not be neglected. Steel production, as well as brick manufacturing, has plenty of scope for improvement in energy efficiency, fuel switching, and technology changes. A combination of two or all three efforts would result in a total reduction of $72 \mathrm{MTCO}_{2}$ in 2030 and $137 \mathrm{MTCO}_{2}$ in 2050 , which is $5 \%$ and $8 \%$ of the total emissions at present respectively. Extended and planned efforts towards the construction industry may lead to higher emission reductions.

Data availability. No data sets were used in this article.

Author contributions. PJ developed the study framework, computed the model results and prepared the draft manuscripts. TM refined the model, verified the findings and manuscripts and supervised the work.

Competing interests. The authors declare that they have no conflict of interest.

Special issue statement. This article is part of the special issue "European Geosciences Union General Assembly 2018, EGU Division Energy, Resources \& Environment (ERE)". It is a result of the EGU General Assembly 2018, Vienna, Austria, 8-13 April 2018.

Acknowledgements. The authors would like to acknowledge the guidance and inputs received from Chandra Venkataraman and Sameer Maithel as well as information sharing. The paper would have been incomplete without kind support of Krishna Malakar and Mousami Prasad. Also, the authors would like to thank Department of Science and Technology (DST) Government of India project no. 11DST078 and Mid-Stage Financial support for TAP Students by Industrial Research and Consultancy Centre (IRCC) of Indian Institute of Technology, Bombay under project 12IRCC001 for financial support.

Edited by: Viktor Bruckman

Reviewed by: two anonymous referees 


\section{References}

Anand, S., Vrat, P., and Dahiya, R. P.: Application of a system dynamics approach for assessment and mitigation of $\mathrm{CO}_{2}$ emissions from the cement industry, J. Environ. Manage., 79, 383398, https://doi.org/10.1016/j.jenvman.2005.08.007, 2006.

Antimiani, A., Costantini, V., and Paglialunga, E.: The sensitivity of climate-economy CGE models to energy-related elasticity parameters: Implications for climate policy design, Econ. Model., 51, 38-52, https://doi.org/10.1016/j.econmod.2015.07.015, 2015.

Asian Development Bank: Key Indicators for Asia and the Pacific 2015: India, The Bank, Manila, Philippines, 2015.

Bhushan, C.: Industry Index: Cement, Centre for Science and Environment, New Delhi, India, 2009a.

Bhushan, C.: Industry Index: Steel, Centre for Science and Environment, New Delhi, India, 2009b.

Central Pollution Control Board: Guidelines on brick manufacturing unit, New Delhi, India, 2013.

Chen, Z., Xue, J., Rose, A. Z., and Haynes, K. E.: The impact of high-speed rail investment on economic and environmental change in China?: A dynamic CGE analysis, Transport. Res. A-Pol., 92, 232-245, https://doi.org/10.1016/j.tra.2016.08.006, 2016.

CMIE: CMIE Industry Outlook, Demand Supply Futur, available at: https://industryoutlook.cmie.com/kommon/bin/sr.php? kall $=$ wshowtab\&icode $=0101013001000000 \&$ tabno $=0005$ (last access: 24 May 2018), 2017.

Dutta, M. and Mukherjee, S.: An outlook into energy consumption in large scale industries in India?: The cases of steel, aluminium and cement, Energ. Policy, 38, 7286-7298, https://doi.org/10.1016/j.enpol.2010.07.056, 2010.

Government of India: India's Intended Nationally Determined Contribution: Working Towards Climate Justice, New Delhi, India, 2015.

Hasanbeigi, A., Price, L., and Lin, E.: Emerging energy-efficiency and $\mathrm{CO}_{2}$ emission-reduction technologies for cement and concrete production: A technical review, Renew. Sust. Energ. Rev., 16, 6220-6238, https://doi.org/10.1016/j.rser.2012.07.019, 2012.

Hasanbeigi, A., Morrow, W., Sathaye, J., Masanet, E., and $\mathrm{Xu}$, T.: A bottom-up model to estimate the energy ef fi ciency improvement and $\mathrm{CO}_{2}$ emission reduction potentials in the Chinese iron and steel industry, Energy, 50, 315-325, https://doi.org/10.1016/j.energy.2012.10.062, 2013.

He, K. and Wang, L.: A review of energy use and energy-efficient technologies for the iron and steel industry, Renew. Sust. Energ. Rev., 70, 1022-1039, https://doi.org/10.1016/j.rser.2016.12.007, 2017.

Hidalgo, I., Szabo, L., Ciscar, J. C., and Soria, A.: Technological prospects and $\mathrm{CO}_{2}$ emission trading analyses in the iron and steel industry?: A global model, Energy, 30, 583-610, https://doi.org/10.1016/j.energy.2004.05.022, 2005.

Hidalgo, I., Ciscar, J. C., and Soria, A.: $\mathrm{CO}_{2}$ emission trading within the European Union and Annex $\mathrm{B}$ countries?: the cement industry case, Energ. Policy, 34, 72-87, https://doi.org/10.1016/j.enpol.2004.06.003, 2006.

INCCA: India: Greenhouse Gas Emissions 2007, Ministry of Environment and Climate Change, New Delhi, India, 2010.

Kumar, S. and Madlener, R.: $\mathrm{CO}_{2}$ emission reduction potential assessment using renewable energy in India Renewable Nuclear
Hydro Gas Thermal Biomass Small hydro Wind, Energy, 97, 273-282, https://doi.org/10.1016/j.energy.2015.12.131, 2016.

$\mathrm{Li}$, W. and Jia, Z.: The impact of emission trading scheme and the ratio of free quota?: A dynamic recursive CGE model in China, Appl. Energ., 174, 1-14, https://doi.org/10.1016/j.apenergy.2016.04.086, 2016.

Maithel, S.: Evaluating Energy Conservation Potential of Brick Production in India, SAARC Energy Centre, Islamabad, Pakistan, 2013.

Ministry of Environment, Forest and Climate Change: India First Biennial Update Report to the United Nations Framework Convention on Climate Change, New Delhi, India, 2015.

Montaud, J., Pecastaing, N., and Tankari, M.: Potential socioeconomic implications of future climate change and variability for Nigerien agriculture?: A countrywide dynamic CGE-Microsimulation analysis, Econ. Model., 63, 128-142, https://doi.org/10.1016/j.econmod.2017.02.005, 2017.

Morrow III, W. R., Hasanbeigi, A., Sathaye, J., and $\mathrm{Xu}$, T.: Assessment of energy ef fi ciency improvement and $\mathrm{CO}_{2}$ emission reduction potentials in India's cement and iron \& steel industries, J. Clean. Prod., 65, 131-141, https://doi.org/10.1016/j.jclepro.2013.07.022, 2014.

Oda, J., Akimoto, K., Tomoda, T., Nagashima, M., and Wada, $\mathrm{K}$.: International comparisons of energy efficiency in power, steel, and cement industries, Energ. Policy, 44, 118-129, https://doi.org/10.1016/j.enpol.2012.01.024, 2012.

Ozawa, L., Sheinbaum, C., Martin, N., Worrell, E., and Price, L.: Energy use and $\mathrm{CO}_{2}$ emissions in Mexico's iron and steel industry, Energy, 27, 225-239, 2002.

Pardo, N., Moya, J. A., and Mercier, A.: Prospective on the energy efficiency and $\mathrm{CO}_{2}$ emissions in the EU cement industry, Energy, 36, 3244-3254, https://doi.org/10.1016/j.energy.2011.03.016, 2011.

Rajarathnam, U., Athalye, V., Ragavan, S., Maithel, S., Lalchandani, D., Kumar, S., Baum, E., Weyant, C., and Bond, T.: Assessment of air pollutant emissions from brick kilns, Atmos. Environ., 98, 549-553, https://doi.org/10.1016/j.atmosenv.2014.08.075, 2014.

Rojas-Cardenas, J. C., Hasanbeigi, A., Sheinbaum-Pardo, C., and Price, L.: Energy ef fi ciency in the Mexican iron and steel industry from an international perspective, J. Clean. Prod., 158, 335-348, https://doi.org/10.1016/j.jclepro.2017.04.092, 2017.

Sathaye, J., Price, L., Can, S. de la R. du, and Fridley, D.: Assessment of Energy Use and Energy Savings Potential in Selected Industrial Sectors in India, Ernest Orlando Lawrence Berkeley Natl. Lab., LBNL-57293(July), Berkeley, CA, USA, 2005.

Shirodkar, N. and Terkar, R.: Stepped Recycling?: The Solution for E-waste Management and Sustainable Manufacturing in India, Mater. Today-Proc., 4, 8911-8917, https://doi.org/10.1016/j.matpr.2017.07.242, 2017.

Tapia-Ahumada, K., Octaviano, C., Rausch, S., and Pérez-Arriaga, I.: Modeling intermittent renewable electricity technologies in general equilibrium models, Econ. Model., 51, 242-262, https://doi.org/10.1016/j.econmod.2015.08.004, 2015.

Venkataraman, C., Brauer, M., Tibrewal, K., Sadavarte, P., Ma, Q., Cohen, A., Chaliyakunnel, S., Frostad, J., Klimont, Z., Martin, R. V., Millet, D. B., Philip, S., Walker, K., and Wang, S.: Source influence on emission pathways and ambient $\mathrm{PM}_{2.5}$ pollution 
over India (2015-2050), Atmos. Chem. Phys., 18, 8017-8039, https://doi.org/10.5194/acp-18-8017-2018, 2018.

Wang, K., Wang, C., Lu, X., and Chen, J.: Scenario analysis on $\mathrm{CO}_{2}$ emissions reduction potential in China's iron and steel industry, Energ. Policy, 35, 2320-2335, https://doi.org/10.1016/j.enpol.2006.08.007, 2007.

Wang, R., Tao, S., Shen, H., Huang, Y., Chen, H., Balkanski, Y., Boucher, O., Ciais, P., Shen, G., Li, W., Zhang, Y., Chen, Y., Lin, N., Su, S., Li, B., Liu, J., and Liu, W.: Trend in Global Black Carbon Emissions from 1960 to 2007, Environ. Sci. Technol., 48, 6780-6787, https://doi.org/10.1021/es5021422, 2014.
Worrell, E., Price, L., and Martin, N.: Energy efficiency and carbon dioxide emissions reduction opportunities in the US iron and steel sector, Energy, 26, 513-536, https://doi.org/10.1016/S03605442(01)00017-2, 2001.

Worrell, E., Price, L., Neelis, M., Galitsky, C., and Nan, Z.: World Best Practice Energy Intensity Values for Selected Industrial Sectors, Lawrence Berkeley National Laboratory, LBNL-62806 Rev2, Berkeley, CA, USA, p. 51, 2007. 